|RA메

Academic Scientific Journals
Samarra Journal of Pure and Applied Science

www.sjpas.com

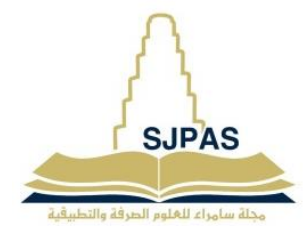

ISSN:2663-7405

\title{
التحري عن وجود بعض المعادن الثقبتة والميكروبات في التوابل
}

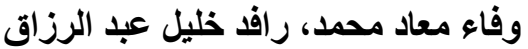

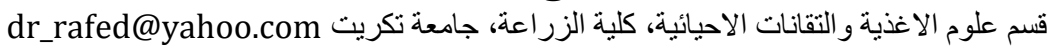

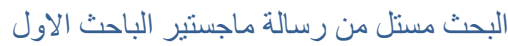

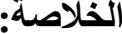

تضدذت الدر اسة جمع 11 ذو عاً من الذو ابل التي تباع في الاسدو اق المحلية لمدينة

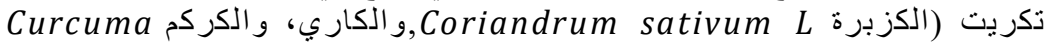

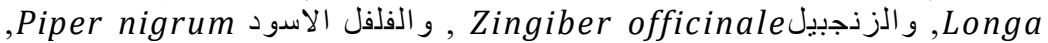

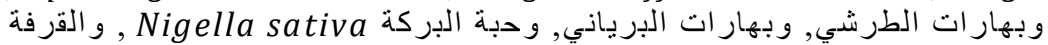

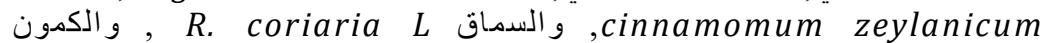

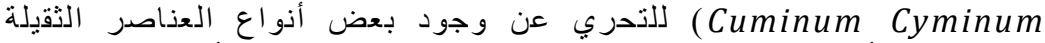

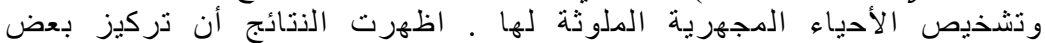

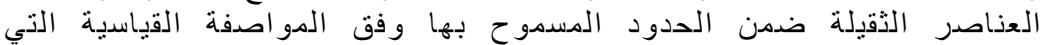

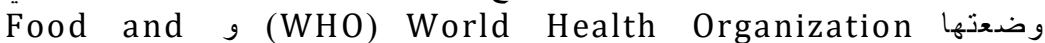
(FAO) Agriculture Organization

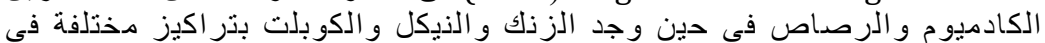

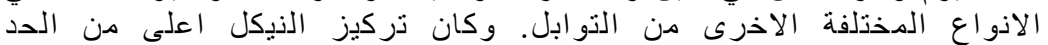

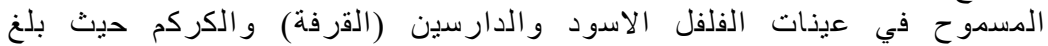
على الذو الي في حين كان تركيز الذيكل في

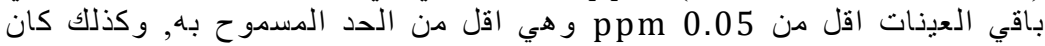

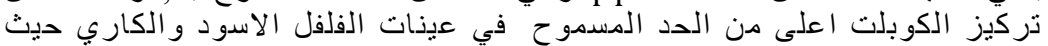

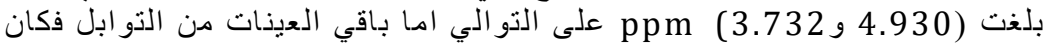

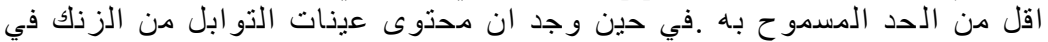

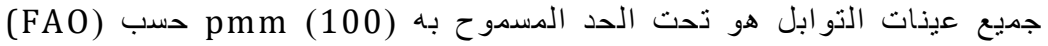

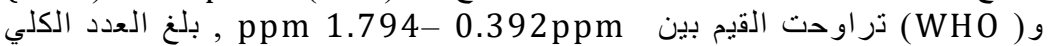

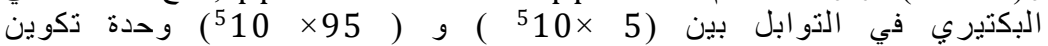

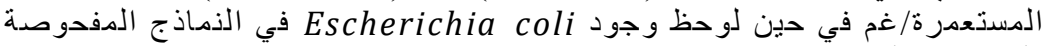

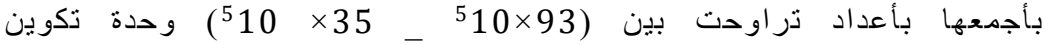

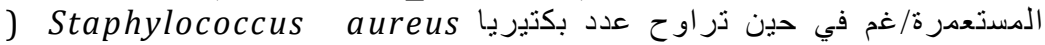

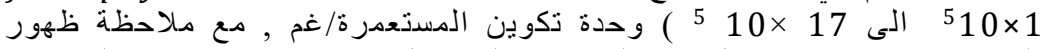

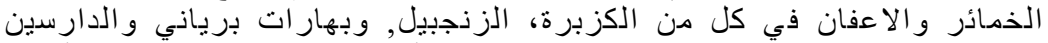

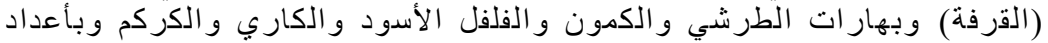

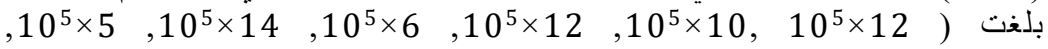

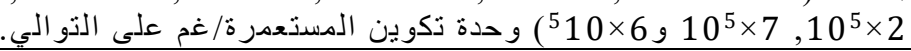

هنالك الكثير من انواع التو ابل التي تستخدم لأغر اض عديدة منها لأغر اض صبدلانية وطبية ومنها لأغر اض اضافتها للطعام لأعطائه

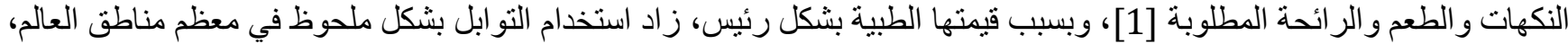
بما في ذللك أوروبا و أمريكا الثمالية. على سبيل المثال، خلال هذه الفترة، نمت الأدوية العثبية في الولايات المتحدة إلى صناعة تبلغ قيمتها في المتوسط 1.5 مليار دولار سنويا، مع نمو سنوي منوقع بنسبة 15 \% [2]. إن عملية التحضير والتداول بمكن أن تجعلها مصدرًا للتلوث وللتسمم الغذائي، ويمكن الحصول على التو ابل التي تُستخدم لتعزيز نكهة الخضروات التهوي في الحساء في اناء الطهي و القلي من اللحاء أو البراعم أو الز هور أو الأوراق أو البذور أو جذور للنباتات [3]. إن وجود المعادن الأساسية في التوابل مثل الحديد

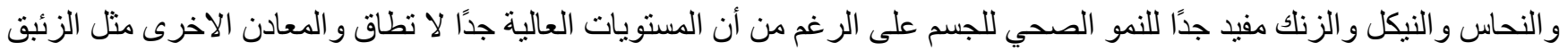
و الرصاص و الكادميوم و غير ها سامة بتركيز ات منخفضة للغاية، وقد يؤدي إضافة التو ابل التي قد تكون ملوثة بالمعادن النزرة و التقيلة 


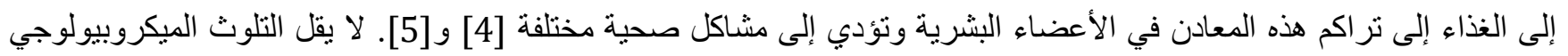

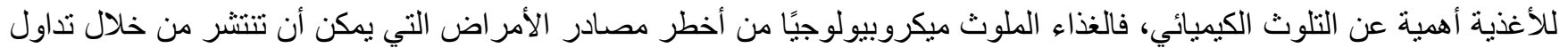

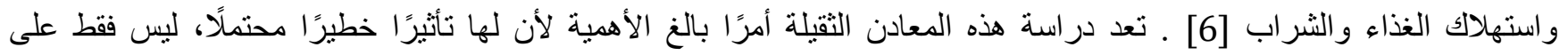

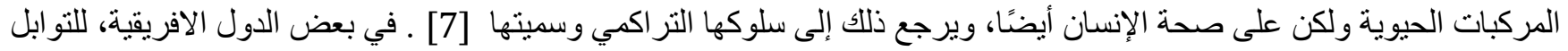

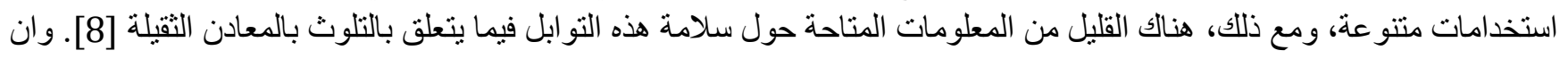

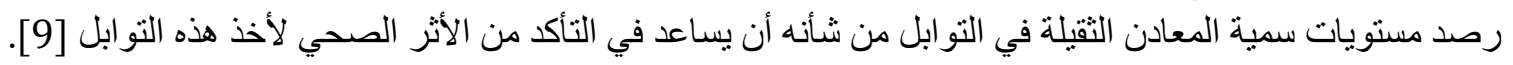

\section{المواد وطرائق العمل} جمع العينات جمعت (11) عينة من التو ابل الجافة في عبو اتها المتوفرة في الأسواق المحلية لمدينة تكريت، والجدول (1) يوضح تلك المو اد. جدول (1) عينات التو ابل الجافة

\begin{tabular}{|c|c|c|c|}
\hline تاريخ الاتتهاء & تاريخ الإتتاج & العلامة & التو ابل \\
\hline $2022 / 6$ & $2020 / 6$ & الطباخ & كزبرة (مسحوق) \\
\hline $2022 / 5$ & $2020 / 5$ & 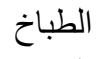 & كاري (مسحوق) \\
\hline $2022 / 7$ & $2020 / 7$ & الطباخ & كركم (مسحوق) \\
\hline $2022 / 7$ & $2020 / 7$ & الطباخ & كمون (مسحوق) \\
\hline $2022 / 5$ & $2020 / 5$ & الطباخ & زنجبيل (مسحوق) \\
\hline $2022 / 6$ & $2020 / 6$ & الطباخ & دارسين(القرفة) (مسحوق) \\
\hline $2023 / 4$ & $2020 / 4$ & كربلاء & حبة سودة (مسحوق) \\
\hline $2022 / 7$ & $2020 / 7$ & 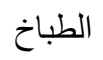 & فلفل اسود (مسحوق) \\
\hline $2022 / 8$ & $2020 / 8$ & الطباخ & سماق احمر(مسحوق) \\
\hline $2022 / 7$ & $2020 / 7$ & الطباخ & بهار ات برياني (مسحوق) \\
\hline $2021 / 7$ & $2019 / 8$ & الطباخ الط & بهار ات طرشي (مسحوق) \\
\hline
\end{tabular}

تقدير محتوى التوابل من العناصر الثقيلة

قدر محتوى التو ابل من المعادن الثقبلة باستعمال جهاز Atomic absorption spectrophotometer الأمريكي الصنع في

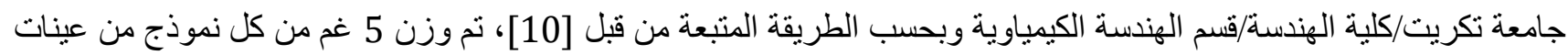

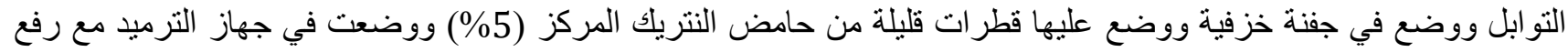

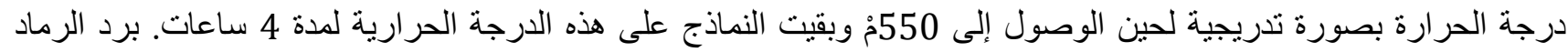

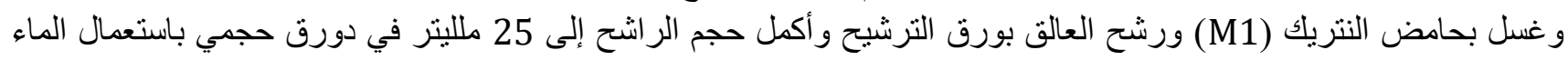

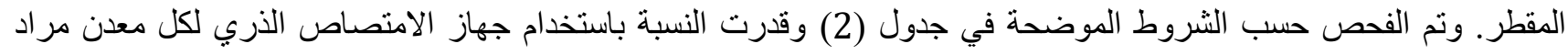

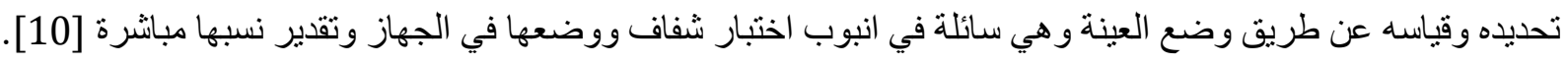
جدول (2) شروط العمل في جهاز الامتصاص الذري خلال التحليل

\begin{tabular}{|c|c|c|c|c|c|c|c|c|}
\hline حد الكثف (ppm) & اللمبة & الحرق(L/min تدفق غاز & الحرق & المؤكسد & $\begin{array}{l}\text { شالتيار } \\
\text { Ma) }\end{array}$ & $\begin{array}{c}\text { عرض } \\
\text { (nm) } \\
\end{array}$ & $\begin{array}{l}\text { الموجة } \\
\text { (nm) } \\
\text { (nm }\end{array}$ & العنصر \\
\hline 0.05 & D2 & 2 & استيلين & هواء & 10 & 0.7 & 283.3 & $\mathrm{~Pb}$ \\
\hline 0.05 & ديتريوم D2 & 1.8 & الأستيلين & هو اء & 8 & 0.7 & 213.9 & $\mathrm{Zn}$ \\
\hline 0.05 & ديثريوم D2 & 1 & الاستيلين & هواء & 8 & 0.7 & 228.8 & $\mathrm{Cd}$ \\
\hline 0.05 & ديتربود -D2 & 2 & الاستيلين & هواء & 12 & 0.2 & 240.7 & Co \\
\hline 0.05 & ديتريوم-D2 & 2 & الاستيلين & هو اء & 12 & 0.2 & 232.0 & $\mathrm{Ni}$ \\
\hline
\end{tabular}




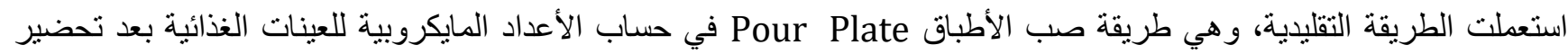

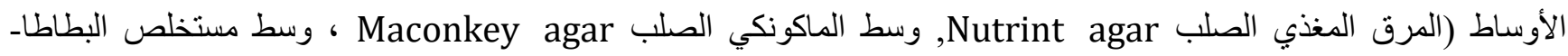

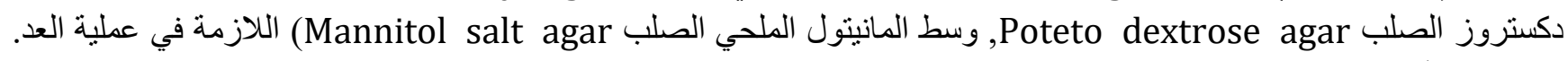

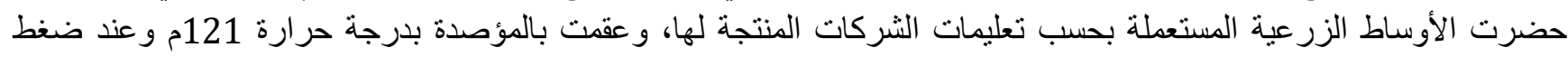
100 كيلوباسكال فوي الضغط الزوري الجوي لمدة 15 دقيقة.

VITEK 2- التشخيص بنظام شخصت الانواع البكتيرية التي اعنمدت في الدراسة بنظام (VITEK2) وذللك للناكد من الانواع البكتيرية بالطر ائق التشخيصية

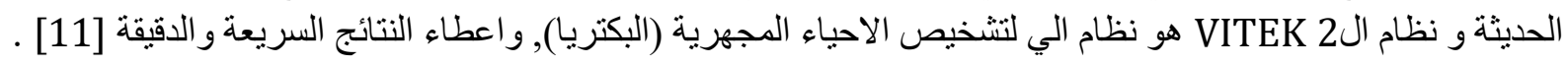

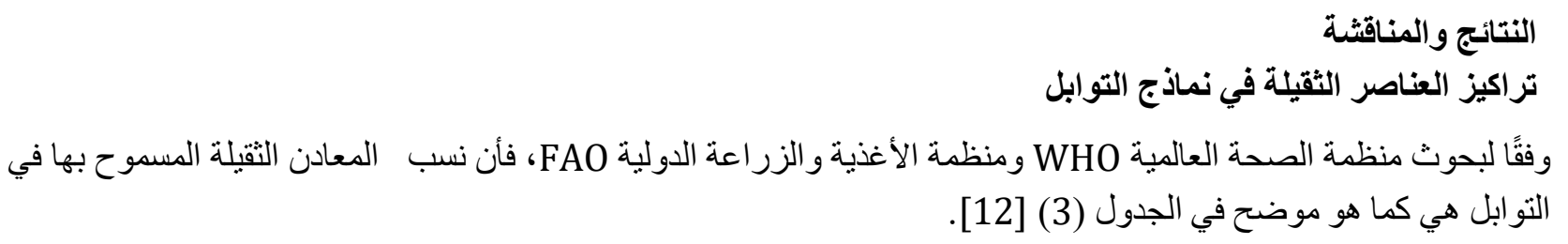
جدول (3) الحدود المسموح بها للمعادن الثقيلة (ppm) في التو ابل وحسب ( WHO / FAO )

\begin{tabular}{|c|c|}
\hline الحدود المسموح بها للمعادن الثقيلة"ppm & المعادن المدروسة \\
\hline 5 & الرصاص \\
\hline 0.2 & 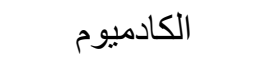 \\
\hline 1.63 & 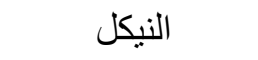 \\
\hline 3.5 & 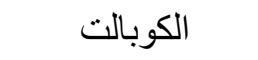 \\
\hline 100 & 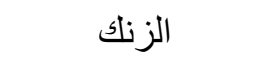 \\
\hline
\end{tabular}

يوضح الجدول (4) العناصر المعدنية في مجموعة التوابل التي تم فحصها والتي حملت جميعها علامة الطباخ فيما عدا حبة البركة

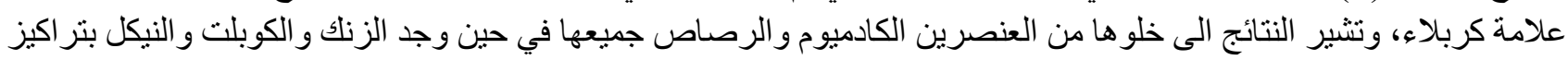

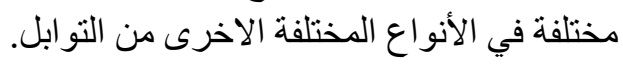


جدول (4) تراكيز العناصر الثقيلة ppm الملوثة لبعض أنواع التوابل

\begin{tabular}{|c|c|c|c|c|c|}
\hline $\mathrm{Cd}$ & Co & $\mathrm{Pb}$ & $\mathrm{Ni}$ & $\mathrm{Zn}$ & العينات \\
\hline Ppm & Ppm & Ppm & Ppm & Ppm & \\
\hline$<0.05$ & 4.930 & $<0.05$ & 4.959 & 1.499 & فلفل اسود \\
\hline$<0.05$ & 1.574 & $<0.05$ & 2.740 & 0.442 & كركم \\
\hline$<0.05$ & 3.732 & $<0.05$ & $<0.05$ & 1.278 & كاري \\
\hline$<0.05$ & 1.334 & $<0.05$ & $<0.05$ & 1.106 & بهار ات طرشي \\
\hline$<0.05$ & 1.574 & $<0.05$ & $<0.05$ & 1.179 & بهار ات برياني \\
\hline$<0.05$ & 2.053 & $<0.05$ & 3.850 & 1.7948 & دارسين(القرفة) \\
\hline$<0.05$ & 2.293 & $<0.05$ & $<0.05$ & 0.565 & كمون \\
\hline$<0.05$ & 3.012 & $<0.05$ & $<0.05$ & 1.671 & حبة سودة \\
\hline$<0.05$ & 2.773 & $<0.05$ & $<0.05$ & 0.614 & كزبرة \\
\hline$<0.05$ & 2.053 & $<0.05$ & $<0.05$ & 0.392 & زنجبيل \\
\hline$<0.05$ & $<0.05$ & $<0.05$ & $<0.05$ & 1.524 & سماق \\
\hline
\end{tabular}

يلاحظ من الجدول (4) ان بعض عينات التو ابل، احتوت على تركيز من النيكل اعلى من الحد (1.63) ppm المسموح بهاه و المحدد

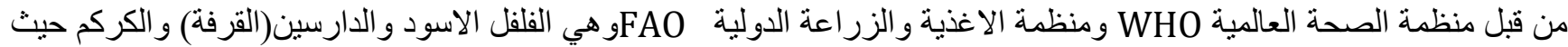

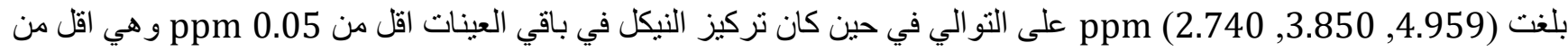

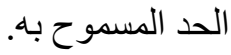

اما محتوى العينات من الكوبلت فيلاحظ من الجدولين (4) ان تركيز الكوبلت اعلى من الحد (3.5) ppm المسموح به و المحدد من

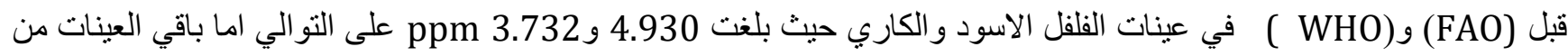

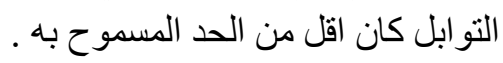

يتضح من الجدول (4) ان نركيز الزنك في جميع عينات التوابل هو تحت الحد المسموح به (100) pmm حسب (FAO) و .ppm وكانت القيم بين ( 0.392 (WHO)

اشارت [13] ان تر اكيز العناصر النيكل و الزنكو والكوبلت كانت ادنى من الحد المسموح به في عينات التوابل (الكركم , القرفة ,

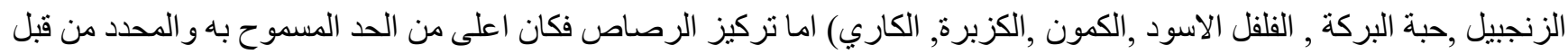

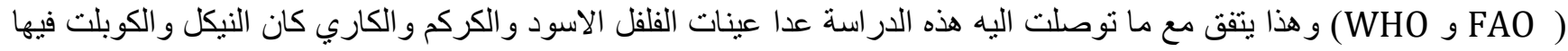

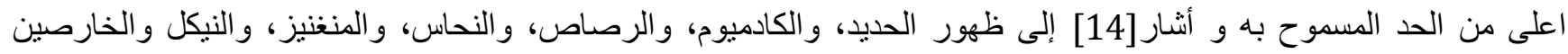

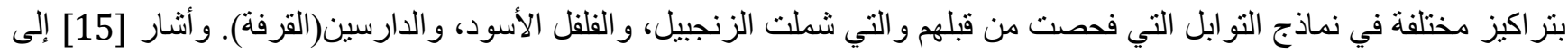

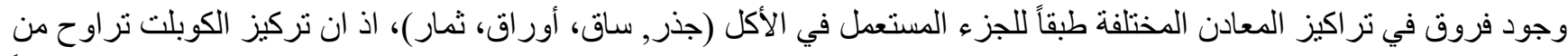

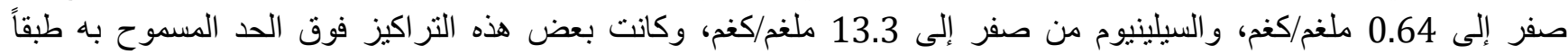

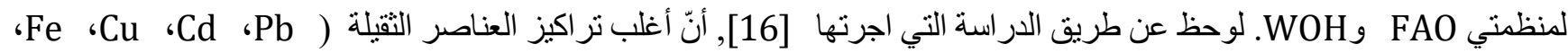
في التوابل التي تم الحصول عليها كانت ضمن الحدود المسموح بها، فيما عدا الكركم الذي كان تركيز الرصاص به به بعادل 


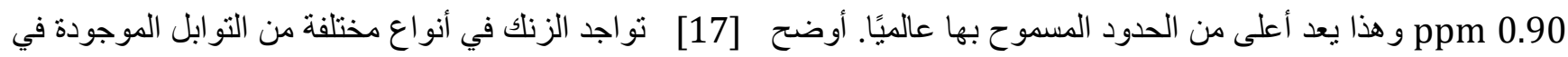

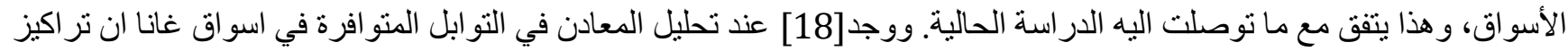

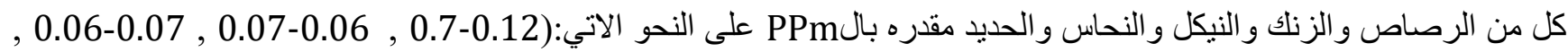

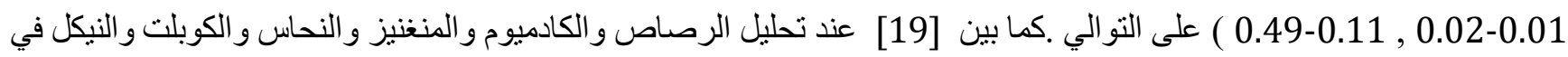

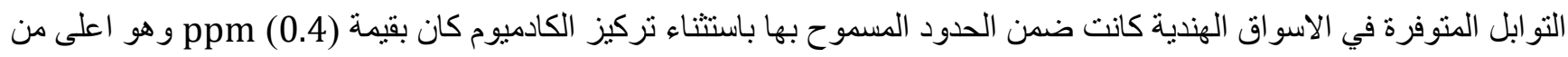
الحد المسموح به حسب FAO و و

\section{تراكيز واعداد الاحياء المجهرية في نماذج التوابل}

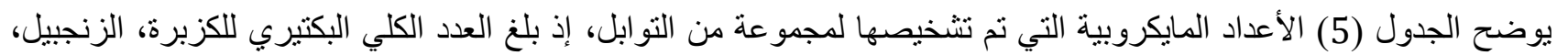

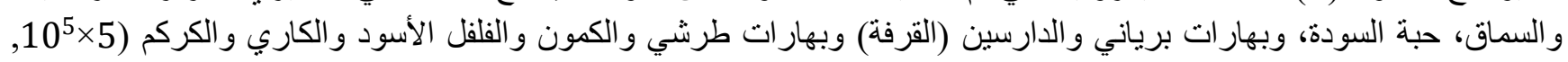

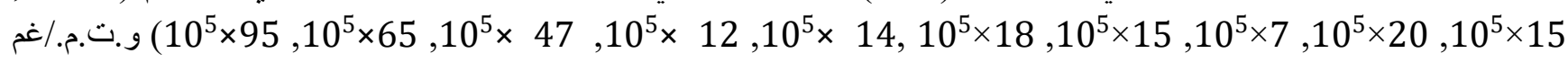

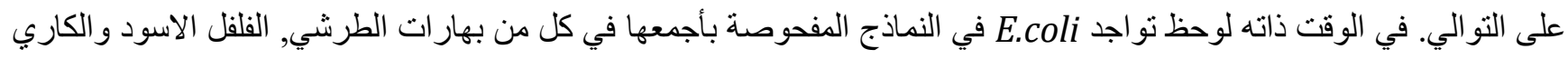

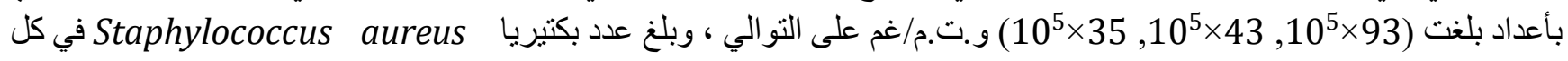

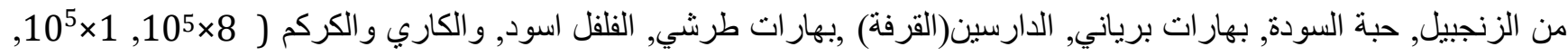

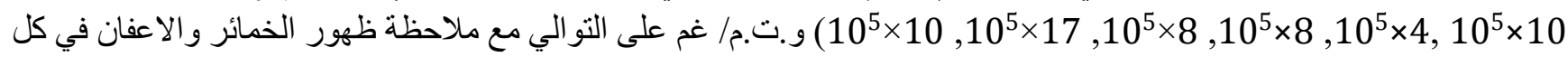

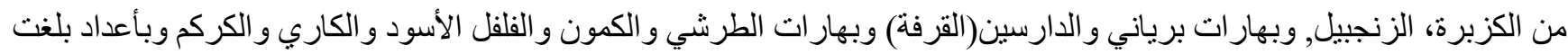

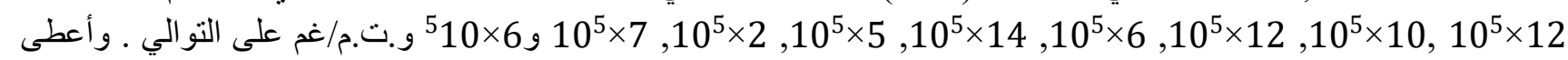

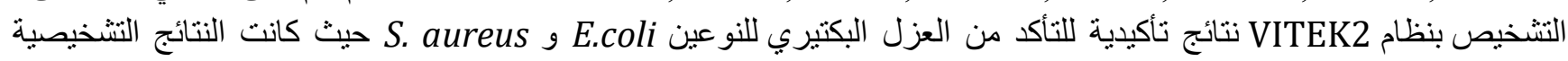
للنو عين بنسبة \% 93 و \% 87 على التو الي.

الأعداد الميكروبية للأحياء المجهرية الملوثة في نماذج التوابل

الجدول (5)

\begin{tabular}{|c|c|c|c|c|c|}
\hline للفطرياّت العدد & لبكتريًا العدد & $\begin{array}{c}\text { العدد الكلي لبكتريا } \\
\text { Staphylococcus } \\
10^{5} \text { x aureus }\end{array}$ & العلي العدد & العينات & $ت$ \\
\hline $10^{5} \times 12$ & - & - & $10^{5} \times 5$ & كزبرة & 1 \\
\hline $10^{5} \times 10$ & - & $10^{5} \times 8$ & $10^{5} \times 15$ & زنجبيل & 2 \\
\hline- & - & - & $10^{5} \times 20$ & سماق & 3 \\
\hline- & - & $10^{5} \times 1$ & $10^{5} \times 7$ & حبة سودة & 4 \\
\hline $10^{5} \times 12$ & - & $10^{5} \times 10$ & $10^{5} \times 15$ & بهار ات برياني & 5 \\
\hline $10^{5} \times 6$ & - & $10^{5} \times 4$ & $10^{5} \times 18$ & دارسين(القرفة) & 6 \\
\hline $10^{5} \times 14$ & $10^{5} \times 93$ & $10^{5} \times 8$ & $10^{5} \times 14$ & بهار ات طرشي & 7 \\
\hline $10^{5} \times 5$ & - & - & $10^{5} \times 12$ & كمون & 8 \\
\hline $10^{5} \times 2$ & $10^{5} \times 43$ & $10^{5} \times 8$ & $10^{5} \times 47$ & فلفل اسود & 9 \\
\hline $10^{5} \times 7$ & $10^{5} \times 35$ & $10^{5} \times 17$ & $10^{5} \times 65$ & كاري & 10 \\
\hline $10^{5} \times 6$ & - & $10^{5} \times 10$ & $10^{5} \times 95$ & كركم & 11 \\
\hline
\end{tabular}




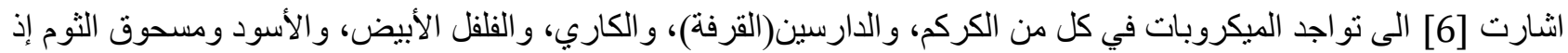

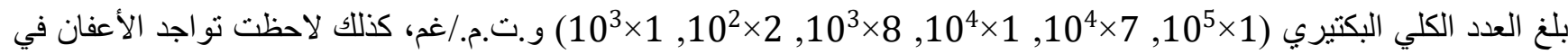

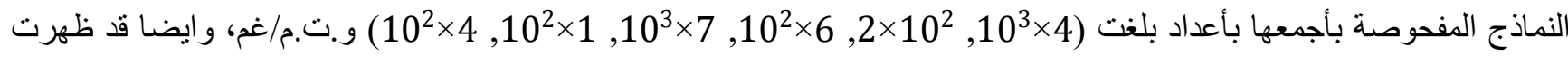
Staphylococcus aureus

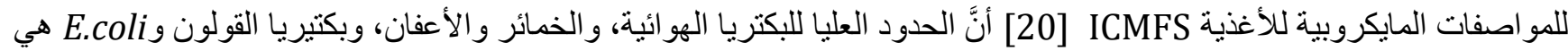

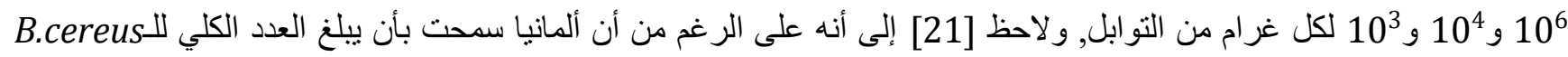

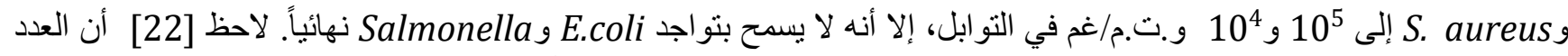

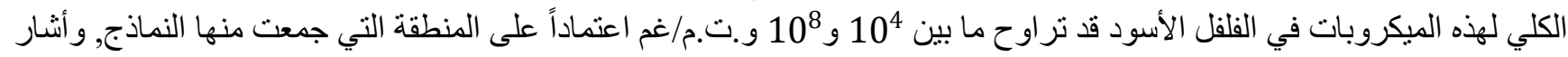

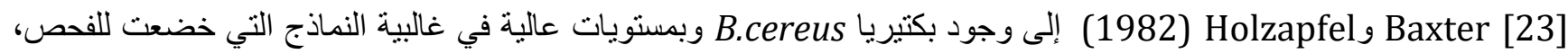

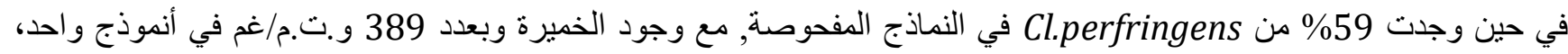

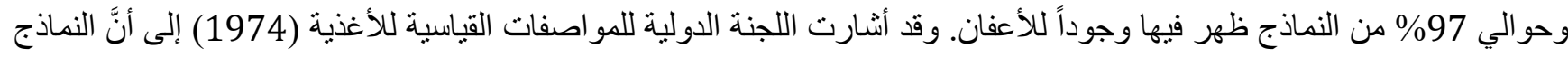

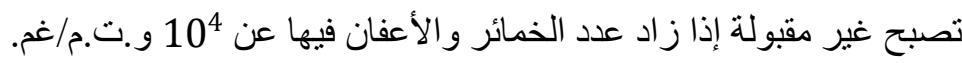

وقد أثنار [24] إلى أنَّ حوالي 32\% من نماذج البهارات المفحوصة ملوثة ببكتيريا العائلة المعوية Enterobacteriaceae مع معاد

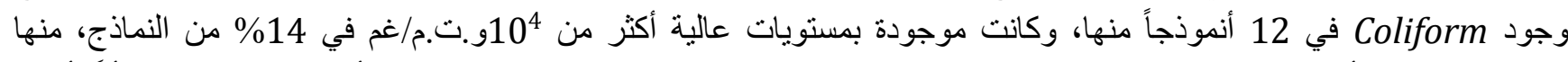

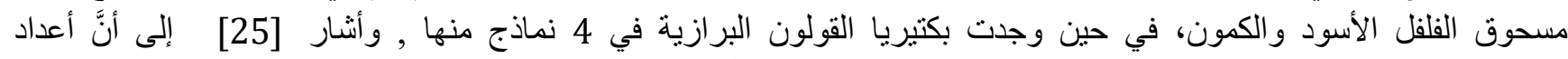
Enterobacteriaceae

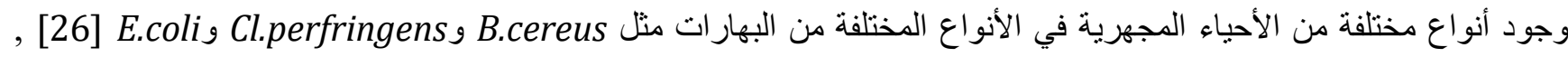

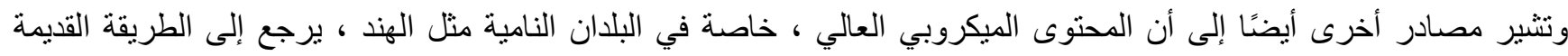

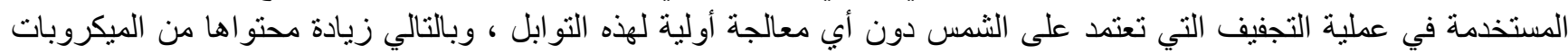

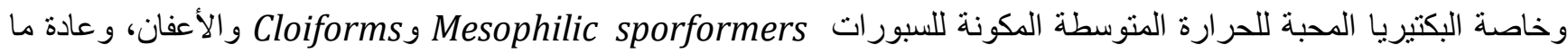

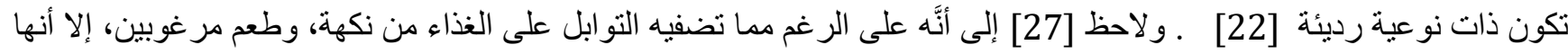

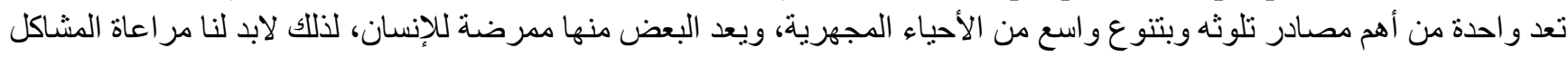
و المخاطر التي من المكن أن تسبيها.

1. عبد المنعم حمد مجيد، رفاه رزوق حميد و نور عصام عبدالرزاق. (2015). التركيب الكيميائي و التغذوي لنبات الكركم. مجلة جامعة الانبار للعلوم الصرفة. المجلد التاسع، العدد الثالث.

2. Abebe W. (2006). Potential health benefits of spices used in Ethiopian cuisines. Ethiopian Medical Journal, 44(2), 133-138.

3. Hinneburg I., Dorman H. D., \& Hiltunen R. (2006). Antioxidant activities of extracts from selected culinary herbs and spices. Food chemistry, 97(1), 122-129.

4. Kumar, S. (2011). Occupational, environmental and lifestyle factors associated with spontaneous abortion. Reprod. Sci., 18, 915-930.

5. Arifa, T.; Isbah, H.; Madiha, A. and Bushra, M. (2012). Microbial Assessment of uncooked and cooked rice samples Available in local markets of Lahore. Pak. J. Bot., 44: 267-270.

6. عبدالحميد, زهر اء ظافر, (2016). الكثف عن أنو اع الملوثات المعدنية و المايكروبية في بعض الأغذية منخفضة الرطوبة

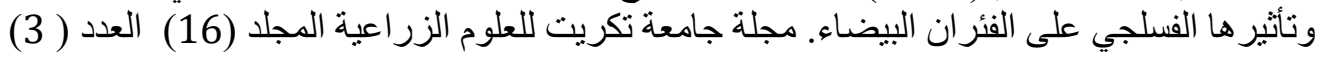

7. Ozkutlu F., Sekeroglu N., \& Kara, S. M. (2006). Monitoring of cadmium and micronutrients in spices commonly consumed in Turkey. Research Journal of Agriculture and Biological Sciences, 2(5), 223-226.

8. FAO,(2009). Corporate document repository plants as storage pesticides

9. Nkansah M. A., \& Amoako C. O. (2010). Heavy metal content of some common spices available in markets in the Kumasi metropolis of Ghana. American Journal of Scientific and Industrial Research, 1(2), 158-163. 
10. Radwan M.A. and Salama A.K. (2006). Market basket survey for some heavy metals in Egyptian fruits and vegetables. Food and chemical toxicology. 44 (8) : 1273 - 1278.

11. Doern, G. V. Brueggemann, A. B. Perla, R. Daly, J. Halkias, D. Jones, R. N.and Sauboll, M. A. (1997) Multicenter laboratory evaluation of the bioMérieux Vitek antimicrobial susceptibility testing system with 11 antimicrobial agents versus members of the family Enterobacteriaceae and Pseudomonas aeruginosa. Journal of clinical microbiology, 35(8): 2115-2119.

12. FAO/WHO.(2010).Joint FAO/WHO Food Standards Programme Codex Committee On Contaminants In Foods. Working Document For Information And Use In Discussions Related To Contaminants And Toxins In The GSCTF.

13.رحمة. سها .(2016). الكثف عن بعض المعادن الثقيلة في التوابل المصنَّة المحليّة. مجلة جامعة البعث المجلد 83 العدد

14. Umar, M.A and Salihu, Z.O.(2014).heavy metals content of some spices available within FCT-Abuja,Nigeria. International Journal of Agricultural and food science.4(1):66-74.

15. Al-Eed, M. A., Assubaie, F. N., El-Garawany, M. M., El-Hamshary, H., \& El-Tayeb, Z. M. (1997). Determination of heavy metal levels in common spices. Research Journal of Agriculture and Biological Sciences, 2(5), 223-226.

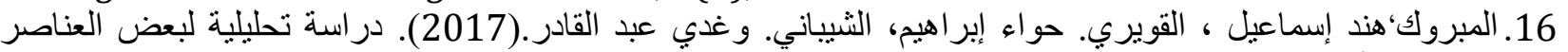

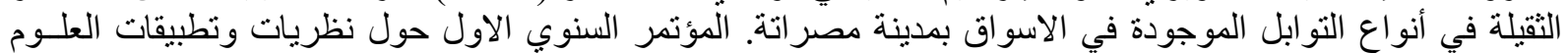

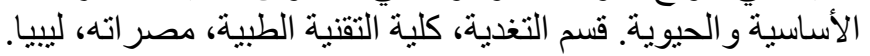

17. Darko, B.; Ayim, I. and Voegborlo, (2014). Heavy metal content in mixed and unmixed seasonings in the Ghanaian market. African Journal of food and Science, 8 (1): 14-19.

18. Nkansah, M. A., \& Amoako, C. O. (2010). Heavy metal content of some common spices available in markets in the Kumasi metropolis of Ghana. American Journal of Scientific and Industrial Research, 1(2), 158-163.

19. Inam F., Deo, S., \& Narkhede N. (2013). Analysis of minerals and heavy metals in some spices collected from local market. J. of. Phar. and Bio. Sci, 8(2), 40-43

20. ICMSF (International Commission on Microbiological Specifications for Foods). (1974). Microorganisms in foods, vol. 2. Sampling for microbiological analysis: principles and specific applications. Toronto, Canada: University of Toronto Prees.

21. Jarvis, B.(1989). Statistical aspects of the microbiological analysis of foods, vol. 21. Progress in industrial microbiology. Amsterdam: Elsevier.

22. Krishnaswamy, M. A. Patel, J. D., Nair, K. K. S., \& Muthu, M.(1974). Microbioloogical quality of certain spices. Indian Spices, 11,6-8

23. Baxter R., \& Holzapfel W. H. (1982). A microbial investigation of selected spices, herbs, and additives in South Africa. Journal of Food Science, 47(2), 570-574.

24. Banerjee M., \& Sarkar P. K. (2003). Microbiological quality of some retail spices in India. Food Research International, 36(5), 469-474.

25. Adams, M. R., \& Moss, M. O. (1995). Food Microbiology. Cambridge, bUK: The Royal Society of Chemistry

26. Schwab A. H., Harpestad, A. D., Swartzentruber, A., Lanier, J. M., Wentz, B. A., Duran, A. P., ... \& Read Jr, R. B. (1982). Microbiological quality of some spices and herbs in retail markets. Applied and Environmental Microbiology, 44(3), 627-630

27. Betts R. (2014). Microbial herbs and Spices International Food hygiene, 25(1): 9 - 11. 


\title{
Investigate the presence of some heavy metals and microbes in spices
}

\author{
Wafaa Muaad Mohammed* and Rafid Khalil Abdul -Rezzak \\ Food Science, College of Agriculture, Tikrit University (dr_rafed@yahoo.com)
}

\section{Article Information $\quad$ Abstract}

Received: 30/05/2021

Accepted: 15/07/2021

\section{Keywords:}

spices, Microbiology, atomic absorption, Heavy Metals
The study included collecting of 11 types of spices. That are sold in the local markets of Tikrit (coriander, curry, turmeric, ginger, black pepper, tarshi spices, biryani spices, nigella sativa, cinnamon, and sumac) to investigate the presence of some types of heavy elements and to diagnose the microorganisms contaminating them. The results showed that the concentration of some heavy elements is within the permissible limits according to the standard set by the World Health Organization and the Food and Agriculture Organization. The results indicate that they are all free of the two elements, cadmium and lead, while zinc, nickel and cobalt were found in different concentrations in other different types of spices. The concentration of nickel was higher than the permissible limit of black pepper, threshing, and turmeric samples, reaching $(4.959,3.850,2.740) \mathrm{ppm}$, respectively, while the nickel concentration in the rest of the samples was less than $0.05 \mathrm{ppm}$, which is less than the permissible limit. In addition, the cobalt concentration was higher than the permissible limit in black pepper and curry samples with 4.930 and $3.732 \mathrm{ppm}$, respectively, while the rest of the spices samples were less than the permissible limit. It was found that the content of spice samples of zinc in all spice samples being under the permissible limit (100) pmm according to (FAO and WHO) and the values were between $0.392-1.794 \mathrm{ppm}$.The total number of bacteria in the spices was between $\left({ }^{5} 10 \times 5\right)$ and $\left({ }^{5} 10 \times 95\right)$ and $\mathrm{CFU} / \mathrm{gm}$, the presence of E.coli was observed in the whole examined samples with numbers ranging $\left({ }^{5} 10 \times 35+{ }^{5} 10 \times 93\right) \mathrm{CFU} / \mathrm{gm}$, while the number of bacteria (Staphylococcus aureus) was $\left(1 \times{ }^{5} 10\right.$ to $\left.{ }^{5} 10 \times 17\right)$. 